Bangladesh Rice J. 22 (1) : 9-23, 2018

\title{
Effect of Seed Rate on Seedling Quality for Mechanical Rice Transplanting
}

\author{
M A Hossen ${ }^{1 *}$, M M Hossain², M E Haque ${ }^{3}$ and R W Bell ${ }^{4}$
}

\begin{abstract}
A study was conducted in the Farm Machinery and Postharvest Technology Division, Bangladesh Rice Research Institute (BRRI), Gazipur in the irrigated dry season (Boro) of 2012-13. It was aimed at identifying the optimum seed rate of different graded rice variety for mat type seedlings preparation and suitable seedling adjustment option of the rice trans planter to maintain required number of seedlings dispensed per stroke by the rotary picker of the trans planter. Walk behind type 4-rows rice trans planter (DP 480) was used to conduct the study. The experiment was followed as two factorial completely randomized design (CRD) with three replications. Three categories of rice variety as short and bold grain (cv. BR3), medium and slender grain (cv. BRRI dhan28) and extra-long and slender grain (cv. BRRI dhan50) were considered as main factor whereas seed rate of 100, 120, 130, 140, 150 and $160 \mathrm{~g}$ pertray $(280 \times 580 \times 25 \mathrm{~mm})$ were considered as sub-factor. Irrespective of rice category, seedling emergence decreased with the increase of seed rate. Seedling emergence decreased from 77 to 56,74 to 57 and 77 to $54 \%$ in BR3, BRRI dhan 28 and BRRI dhan29 respectively with the increase of seed rate from 100 to $160 \mathrm{~g}$ per tray. Seed rate did not affect the seedling height significantly whereas it was varied with the rice verities only and BRRI dhan 50 produced higher seedling length. However, number of leaf, stem thickness and shoot dry weight decreased and root-shoot ratio increased significantly with the increase of seed rate. The highest shoot dry weight was observed in BR3 followed by BRRI dhan 50 . Seedling strength also decreased with the increase of seed rate. The highest seedling strength $\left(0.043 \mathrm{mg} \mathrm{cm}^{-1}\right)$ was observed for the seed rate of $100 \mathrm{~g}$ of BR3 and the lowest $(0.020$ $\mathrm{mg} \mathrm{cm}^{-1}$ ) for the seed rate of $160 \mathrm{~g}$ of BRRI dhan28. The number of seedling increased and percentage of missing hills decreased with the increase of both the seed rate and seedling adjustment option of the rice transplanter irrespective of variety. In case of BR3, seedling dispensed per stroke and percentage of missing hills varied from 4.3 to 5.7 and 6.8 to 7.8 for the seed rates of 140, 150 and $160 \mathrm{~g}$ of seeds tray ${ }^{-1}$ for 5 to 7 seedling adjustment option of the rice transplanter respectively. Seedlings per stroke and percentage of missing hills of BRRI dhan 28 for the seed rate of 130, 140 and $150 \mathrm{~g}$ of seeds tray ${ }^{-1}$ was found almost same for 5 to 7 seedling adjustment options of the rice transplanter (4.2 to 6.3 and 5.7 to 9.8). However, there was minimum difference of seedlings per stroke and percentage of missing hills among 120, 130 and $140 \mathrm{~g}$ of seeds tray ${ }^{-1}$ for the option of 4 to 7 (4.0 to 5.6 and 3.9 to 7.8 respectively) for BRRI dhan50. It can be concluded that $140 \mathrm{~g}$ of seeds tray ${ }^{-1}$ for short and bold grain (BR3) and $130 \mathrm{~g}$ of seeds tray ${ }^{-1}$ for medium and slender grain (BRRI dhan28) under the seedling adjustment options of 5 to 7 and $120 \mathrm{~g}$ of seeds tray ${ }^{-1}$ for extra-long and slender grain (BRRI dhan50) under the seedling adjustment options of 4 to 7 may be used for desired seedlings per hill and minimum missing hills along with good quality of seedling.

Key words: Rice variety, seed rate, seedling quality, seedling strength, rice transplanter.
\end{abstract}

\section{INTRODUCTION}

Bangladesh is predominantly an agrarian country. Agriculture plays a vital role in her economy in terms of food security, value addition, employment and export earning, like many other Asian countries. Agricultural contribution to the economy has been declining over the decade (Kabir, 2005). The dominant food crop of Bangladesh is rice, accounting for about 75 percent of agricultural land use and 28 percent of GDP (Munir and Muaz, 2008).

\footnotetext{
${ }^{1}$ Farm machinery and Postharvest Technology Division, BRRI, Gazipur. ${ }^{2}$ Department of Farm Power and Machinery, BAU, Mymensingh. ${ }^{3}$ Murdoch University Project Implementation Office, Uttara, Dhaka, Bangladesh and ${ }^{4}$ School of Veterinary and Life Sciences, Murdoch University, Murdoch, WA 6150 Australia. *Coresponding author's E-mail: ahossenbrri@gmail.com
} 
Historically, rice cultivation is a labourintensive task that could not be accomplished easily. Labour cost accounts for the highest input cost in rice production (Clayton, 2010). Bangladesh agriculture has been facing serious challenges of labour scarcity not only in peak period but also in normal time due to increase innon-farm job opportunities having higher wage, migration of labour force to cities and low status of agricultural labourer in the society (Ziauddin and Ahmmed, 2010). Mechanization is the only option to minimize the labourcrisis during peak and normal time of rice cultivation. Agricultural mechanization using small scale machinery to agricultural production has been one of the outstanding developments in the developed countries (Osunbitana et al., 2005).

Manual transplanting of seedling is the most widely adopted and the most ancient method of rice transplanting. In Bangladesh, rice seedlings are normally transplanted manually by hired labour, which causes labour shortage throughout the peak period of transplanting. The labourers do not care for the plant spacing and keep the plant population at sub optimum level (Mann and Ashraf, 2001).

The total labour requirement for rice production in one hectare of land is $\mathbf{1 5 6 . 2}$ man-days of which 44.5 man-days are consumed by seedling raising and transplanting, which is $28.24 \%$ of the total labour requirement (Rahman, 1997) whereas only 9-10 man-days ha-1 required in mat type seedling raising suitable for mechanical transplanting (Islam et al. 2016). Aged seedling is suitable to uproot and transplant manually, which limits the number of tillering during the growing period. Manual transplanting is tedious and time consuming, which is often the cause of delayed planting. The rice yield loss due to delayed planting were 60,55 and $9 \mathrm{~kg} \mathrm{ha}^{-1}$ day-1 $^{-1}$ in the Boro, Aman and early wet (Aus) seasons, respectively, in Bangladesh (Sattar, 1999). Mechanized rice transplanting is seen as a solution of labour problems. The mechanical transplanting reduces cost, saves labour, ensures timely transplanting and attains optimum plant density that contributes to high productivity (Manjunatha et al., 2009). Both root-washed and soil attached seedling is used for mechanical transplanting. The attached soil with seedling works as bonding elements, which helps to maintain uniformity, stand-up seedlings, reduces transplanting shock and prevents floating, which is crucial prerequisite for mechanical transplanting. The smooth operation of the rotary picker and successful isolation of seedling hills from its mat is largely determined by whether the seedlings were properly bounded by the soil and evenly distributed (CAME, 2007a).

Mechanization of rice cultivation, including seedling raising and transplanting, is expanding in Bangladesh in order to reduce the cost of production. In manual transplanting, 30-40-day-old root washed seedlings are used whereas mat type seedlings are used in mechanical transplanting. Mat type seedlings are raised either on plastic tray $(280 \times 580 \times 25 \mathrm{~mm})$ or on a polythene sheet with the help of frames. The mat type seedlings are raised with $20-25 \mathrm{~mm}$ thick sieved soil layer mixed with farm yard manure or organic manure placed in trays or over polythene sheets. The mat thickness for best results of seedling raising is about $20 \mathrm{~mm}$ (Anoop et al., 2007).

The success of rice transplanter depends on the seedlingquality. However, seeding density in the seedling tray has considerable influence on seedling quality, and hence on plant establishment and the percentage of missing hills in the field after transplanting. Optimal rice seeding rate is also important in the establishment of a uniform stand with an adequate plant population (Runsick and Wilson, 2009).

There are combined effects of seedling adjustment options of the rice transplanter 
and seedling density on number of plants per hills and percentage of missing hills. Rice grain size and shape in terms of length, breadth and length-breadth ratio differs among rice varieties. Thus, a study needs to be conducted to identify the optimum seed rate for quality seedling production to minimize the percentage of missing hills. In addition, suitable seedling adjustment options of the rice transplanter for different seedling densities also need to be identified to maintain optimum number of seedlings per stroke (plants hill-1) by the rotary picker of the transplanter. On the basis of discussion, it was hypothesized that seedling quality would be improved with the desired seed rate of different graded rice varieties that could relate the suitable seedling adjustment options of the rice transplanter for maintaining desired number of seedlings per stroke by the rotary picker of the transplanter.

\section{The objectives of the study}

On the basis of the above discussion, the following objectives were set for the study to-

- Identify the optimum seed rate for different rice variety to produce quality seedlings and minimize the missing hills of mechanical transplanting.

- Identify suitable seedling adjustment optionsto dispense optimum number of seedling per stroke (seedlings hill-1-1) of the rotary picker of rice transplanter

\section{MATERIALS AND METHODS}

This experiment was conducted in the Farm Machinery and Postharvest Technology Division, BRRI, Gazipur during irrigated dry
(Boro) season 2012-13. Seedling growing medium was same for all the treatments.

\section{Seedling raising}

Plastic tray $(280 \times 580 \times 25 \mathrm{~mm})$ was used to raise seedlings. Clod-free sandy loam soil was mixed with organic fertilizer and filled up the trays to a depth of $20 \mathrm{~mm}$. Sprouted seeds were spread uniformly on each tray. Sprouted seeds are ready to broadcast when the radicals and coleoptiles elongate to $1 / 3$ of seed length. After sowing, fine and loose soil was spread over the seeds to 3-5 $\mathrm{mm}$ depth and the trays were kept under shade. After two days, the trays were placed on the ground in the field and irrigated to saturate the soil and allowed to drain the excess water (Fig. 1).

\section{Size and shape of the rice variety}

Table 1 shows the size and shape of the sample paddy was identified in terms of length according to FAO standards (FAO, 1972) along with those used by USDA rice workers (Adair et al., 1973). Rice varieties BR3 (short and bold), BRRI dhan28 (medium and slender) and BRRI dhan50 (extra-long and slender) were selected to conduct the study (Fig. 2)

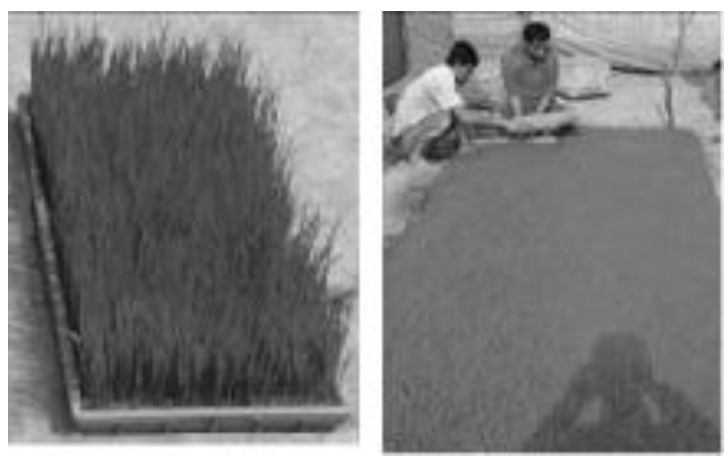

Fig. 1. Seedling raising on plastic tray and polythene sheet.

Table 1. Size and shape of the rice variety.

\begin{tabular}{|c|c|c|c|c|c|}
\hline \multirow[t]{2}{*}{ Variety } & \multicolumn{2}{|c|}{ Average } & \multirow{2}{*}{$\begin{array}{l}\mathrm{L} / \mathrm{B} \\
\text { ratio }\end{array}$} & \multirow{2}{*}{$\begin{array}{c}1000 \text { grain wt at } \\
14 \% \mathrm{mc}(\mathrm{g})\end{array}$} & \multirow[t]{2}{*}{ Type and sub-type } \\
\hline & Length, L (mm) & Breadth, B(mm) & & & \\
\hline BR3 & 8.52 & 3.08 & 2.77 & 27.75 & Short and bold \\
\hline BRRI dhan28 & 9.28 & 2.40 & 3.87 & 22.63 & Medium and slender \\
\hline BRRI dhan50 & 11.48 & 1.85 & 6.21 & 19.64 & Extra-long and slender \\
\hline
\end{tabular}




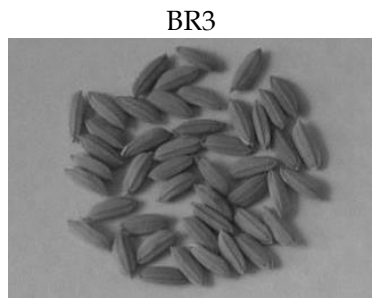

BRRI dhan28

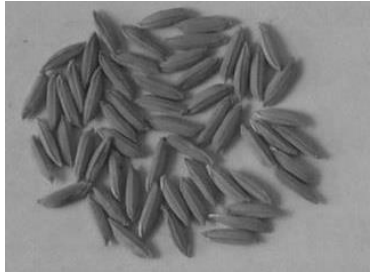

BRRI dhan50

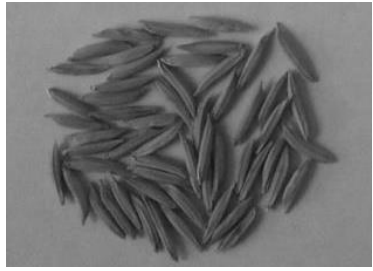

Fig. 2. Size of the rice variety.

\section{General feature of the transplanter}

Korean made walking type 4 rows rice transplanter (DP 480) was used to conduct the study (Fig. 3). Major transplanting specifications of the studied transplanter are-

$\begin{array}{lll}\text { Transplanting mechanism } & : & \text { Rotary } \\ \text { Number of rows } & : & 4 \\ \text { Row to row distance }(\mathrm{mm}) & : & 300 \\ \text { Plant to plant distance }(\mathrm{mm}) & : & 110,130,150 \\ \text { Planting pitch control } & : & \text { Adjustable } \\ \text { Transplanting speed }\left(\mathrm{m} \mathrm{s}^{-1}\right) & : & 0.6 \text { to } 1.0\end{array}$

\section{Experimental design and treatments}

The following treatments were arranged in two factor Completely Randomized Design (CRD) design with three replications. Rice varieties as main factors were short and bold (cv. BR3), medium and slender (cv. BRRI dhan28) and extra-long and slender (cv. BRRI dhan50) whereas seed rates ( $\mathrm{g}_{\text {tray }}{ }^{-1}$ ) as subfactors, were 100, 120, 130, 140, 150 and $160 \mathrm{~g}$.

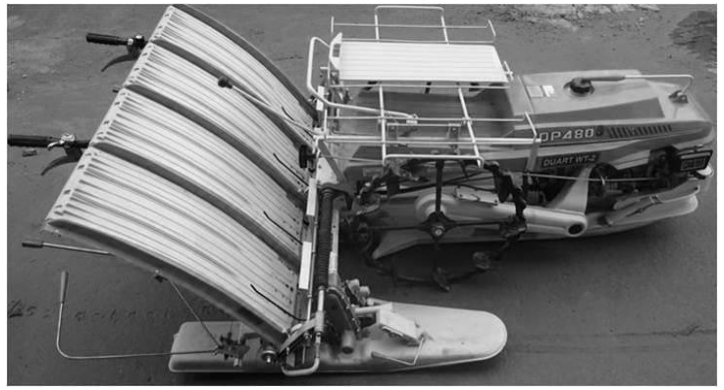

Fig. 3. Walking type 4 rows rice transplanter (DP 480).

\section{Data collection}

Based on the objectives, the following data were collected under three segments of the study-

Seedlings preparation. Germination percentage, number of seeds and seedlings emergence per unit area were calculated at different days of seedling raising.

Seedling quality. Seedling density, seedling height, number of leaves, stem thickness, shoot-dry weight, root-shoot ratio and seedling strength were measured. A 400 $\mathrm{mm}^{2}$ metal sheet boxes was used to determine the seedling density (Fig. 4). Digital slide calipers and scale were used to measure the thickness and height. Seedling strength was measured in terms of $\mathrm{mg} 10 \mathrm{~mm}^{-1}$. Randomly ten plants were collected and dried in the oven for seedling strength measurement. Root-shoot ratio of the raised seedling was also measured in dry condition.

Transplanter performance. Seedlings per hill, damaged seedlings per stroke and percentage of missing hills under different adjustment options of rice transplanter were the parts of transplanting performance. The rice transplanter was used to measure the transplanter performance. The rice transplanter has nine seedling adjustment options. Seedlings of ten strokes under each seedling adjustment options of rice transplanter were collected in tray and analyzed for desired seed rate and transplanting options (Fig. 5). Area of cut per 


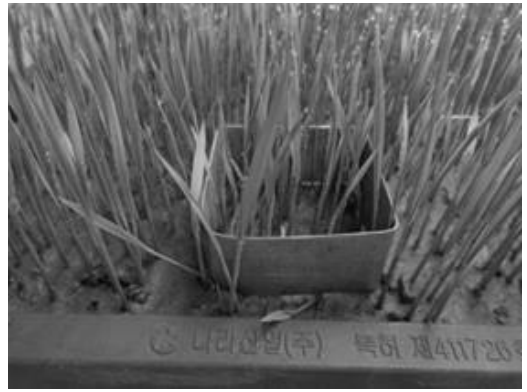

Fig. 4. Seedling density as affected under seed rate and variety.

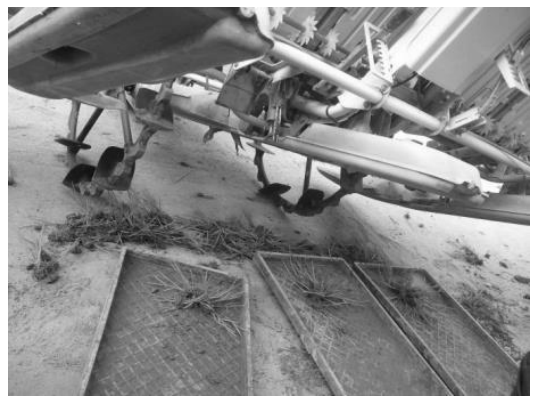
options.

Fig. 5. Operation under different seedling adjustment

stroke of the rotary picker under nine adjustment options was measured (Fig. 6).

Area of cut per stroke of the rotary picker varied with the different seedling adjustment options. Width of cut in every stroke was found same $(12 \mathrm{~mm})$ under nine seedling adjustment options whereas depth of cut per stroke varied with the adjustment options. Area of cut was also determined counting the total number of strokes per tray.

\section{Statistical analysis}

Data were analyzed as a 2-way factorial design (variety $\times$ seed rate) according to Gomez and Gomez (1984) using Crop Stat 7.2 software (IRRI, 2007). Means were compared with least significant difference (LSD) test using Statistix 10 programme (Statistix 10 software, 2013). Simple correlation analysis was carried out with Excel software to determine the relationship of grain yield to yield attributes.

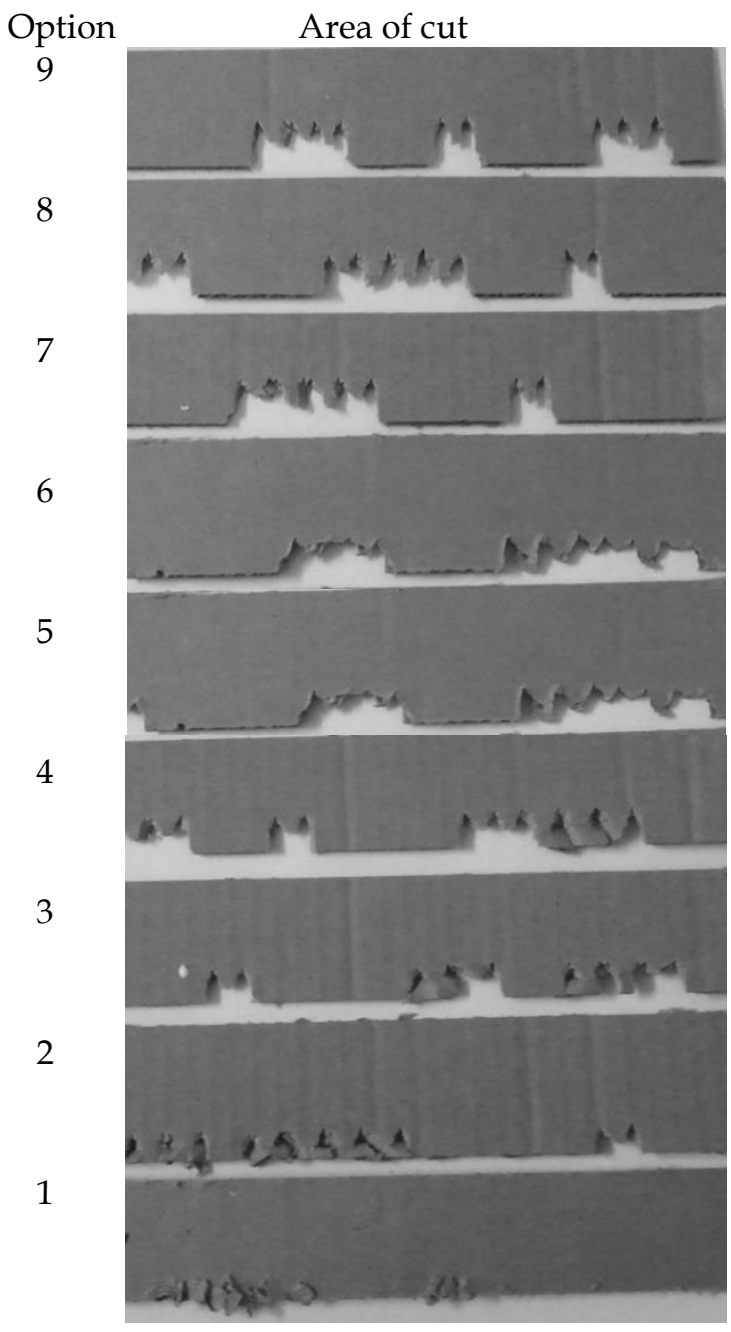

Fig. 6. Stroke area under nine seedling adjustment options of rice transplanter.

\section{RESULT}

\section{Stroke area of the rotary picker}

Stroke area of the rotary picker (area of cut) under nine seedlings pre-adjustment options of the rice transplanter were measured to find out the number of effective stroke per tray and number of trays required per hectare. Width of cut during stroke of the rotary picker under each of the nine seedlings adjustment options was $12 \mathrm{~mm}$ whereas depth of cut per stroke of 
the picker started from $11.2 \mathrm{~mm}$ for options one with the increments of $8.0 \mathrm{~mm}$ with successive options. As seedling adjustment options changed from 1 to 9 , the number of strokes per tray decreased from 1200 to 656 and the number of trays per hectare for transplanting increased from 185 to 339 (Table 2).

\section{Effect of variety and seed rate on seedling density}

Seeds per unit area. Variety and seed rate showed significant effect on seeds per unit area (Table 3). Significantly higher seeds per unit area (5.0) observed for BRRI dhan50 at the seed rate of $160 \mathrm{~g}$ tray-1 followed by $150 \mathrm{~g}^{-1}$ tray $^{-1}(4.7)$ of the same variety whereas lower was for BR3 (2.2) at the seed rate of $100 \mathrm{~g}_{\text {tray }}{ }^{-1}$. BRRI dhan50 and BR3 gave significantly higher (5.0) and lower (3.0) number of seeds tray-1 respectively.

Germinated seeds per unit area (100 $\mathbf{m m}^{2}$ ). Germinated seeds per unit area depended on seed rate and germination percentage of the paddy. The two way interaction of variety and seed rate demonstrated significant variations on number of germinated seeds per unit area as were the single effect of variety and seed rate (Table 4). It was increased linearly with the increase of seed rate. The highest numbers of germinated seeds were observed for BRRI dhan50. It was varied from 2.0 to 3.2 for BR3, 2.3 to 3.7 for BRRI dhan 28 and 2.7 to 4.4 for BRRI dhan50 for the six different seed rates (Table 4).

Seedling density. The two-way interaction of variety and seed rate showed significant effect on seedlings per unit area. The single effect of variety and seed rate was also found significant (Table 5). In case of short and bold grain and medium and slender grain, the highest number of seedling per unit area was observed for $150 \mathrm{~g}$ seeds per tray, which is statistically similar with 130, 140 and $160 \mathrm{~g}$ seed rate and the lowest was observed for $100 \mathrm{~g}$ followed by $120 \mathrm{~g}$ seed rate. No significant difference among 130 to $160 \mathrm{~g}$ seeds tray ${ }^{-1}$ for BRRI dhan28. In case of BRRI dhan 50 , seedling per unit area was not varied with the seed rate of 100 to $160 \mathrm{~g}^{\text {tray }}{ }^{-1}$ whereas 140 and $150 \mathrm{~g}_{\text {tray }}{ }^{-1}$ was found quite similar for BR3.

Table 2. Area of cut per stroke of the rotary picker and number of stroke per tray under nine seedling adjustment options of the transplanter.

\begin{tabular}{|c|c|c|c|c|c|c|}
\hline 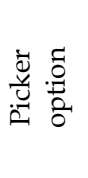 & 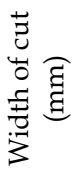 & 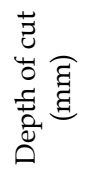 & 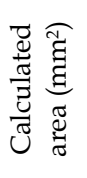 & 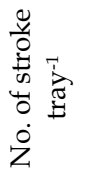 & 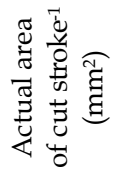 & 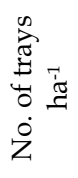 \\
\hline 1 & 12 & 11.2 & 134.4 & 1200 & 135 & 185 \\
\hline 2 & 12 & 12 & 144 & 1132 & 143 & 196 \\
\hline 3 & 12 & 12.8 & 153.6 & 1064 & 153 & 209 \\
\hline 4 & 12 & 13.6 & 163.2 & 996 & 163 & 223 \\
\hline 5 & 12 & 14.4 & 172.8 & 928 & 175 & 239 \\
\hline 6 & 12 & 15.2 & 182.4 & 860 & 189 & 258 \\
\hline 7 & 12 & 17 & 204 & 792 & 205 & 281 \\
\hline 8 & 12 & 18.2 & 218.4 & 724 & 224 & 307 \\
\hline 9 & 12 & 20 & 240 & 656 & 248 & 339 \\
\hline
\end{tabular}

Table 3. Seeds per unit area $\left(100 \mathrm{~mm}^{2}\right)$ as affected by variety and seed rate.

\begin{tabular}{lcccr}
\hline $\begin{array}{l}\text { Seed rate } \\
\left(\text { gtray }^{-1}\right)\end{array}$ & BR3 & $\begin{array}{c}\text { BRRI } \\
\text { dhan28 }\end{array}$ & $\begin{array}{c}\text { BRRI } \\
\text { dhan50 }\end{array}$ & Mean \\
\cline { 2 - 5 } 100 & 2.2 & 2.7 & 3.1 & 2.7 \\
120 & 2.7 & 3.3 & 3.8 & 3.3 \\
130 & 2.9 & 3.5 & 4.1 & 3.5 \\
140 & 3.2 & 3.9 & 4.5 & 3.9 \\
150 & 3.3 & 4.1 & 4.7 & 4.0 \\
160 & 3.6 & 4.4 & 5.0 & 4.3 \\
Mean & 3.0 & 3.6 & 4.2 & - \\
LSD 0.05 & $\mathrm{~V}=0.04, \mathrm{SR}=0.05$ and $\mathrm{V} \times \mathrm{SR}=0.11$ & \\
CV, \% & 1.85 & \multicolumn{4}{c}{} \\
\hline
\end{tabular}

Note: $\mathrm{SR}=$ Seed rate and $\mathrm{V}=$ Variety.

Table 4. Number of germinated seeds per unit area (100 $\mathbf{m m}^{2}$ ) as affected by variety and seed rate.

\begin{tabular}{lcccr}
\hline $\begin{array}{l}\text { Seed rate } \\
\left(\mathrm{g} \text { tray }^{-1}\right)\end{array}$ & BR3 & $\begin{array}{c}\text { BRRI } \\
\text { dhan28 }\end{array}$ & $\begin{array}{c}\text { BRRI } \\
\text { dhan50 }\end{array}$ & Mean \\
\hline 100 & 2.0 & 2.3 & 2.7 & 2.3 \\
120 & 2.4 & 2.8 & 3.3 & 2.8 \\
130 & 2.6 & 3.0 & 3.5 & 3.0 \\
140 & 2.8 & 3.3 & 3.8 & 3.3 \\
150 & 3.0 & 3.5 & 4.1 & 3.5 \\
160 & 3.2 & 3.7 & 4.4 & 3.8 \\
Mean & 2.7 & 3.1 & 3.6 & - \\
LSD $_{0.05}$ & $\mathrm{~V}=0.03, \mathrm{SR}=0.03$ and $\mathrm{V} \times \mathrm{SR}=0.07$ & \\
$\mathrm{CV}, \%$ & 1.31 & \multicolumn{4}{l}{} \\
\hline
\end{tabular}

Note: $\mathrm{SR}=$ Seed rate and $\mathrm{V}=$ Variety. 
Table 5. Number of seedling per unit area $\left(100 \mathrm{~mm}^{2}\right)$ as affected by variety and seed rate.

\begin{tabular}{lcccr}
\hline $\begin{array}{l}\text { Seed rate } \\
\left(\mathrm{g} \mathrm{tray}^{-1}\right)\end{array}$ & BR3 & $\begin{array}{c}\text { BRRI } \\
\text { dhan28 }\end{array}$ & $\begin{array}{c}\text { BRRI } \\
\text { dhan50 }\end{array}$ & Mean \\
\hline 100 & 1.7 & 2.0 & 2.2 & 2.0 \\
120 & 1.9 & 2.2 & 2.3 & 2.1 \\
130 & 2.0 & 2.3 & 2.4 & 2.3 \\
140 & 2.1 & 2.3 & 2.4 & 2.3 \\
150 & 2.2 & 2.6 & 2.5 & 2.5 \\
160 & 2.0 & 2.5 & 2.7 & 2.5 \\
Mean & 1.99 & 2.31 & 2.41 & - \\
LSD $_{0.05}$ & $\mathrm{~V}=0.12, \mathrm{SR}=0.15$ and $\mathrm{V} \times \mathrm{SR}=0.29$ & \\
$\mathrm{CV}, \%$ & 7.83 & & \\
\hline
\end{tabular}

Note: $\mathrm{SR}=$ Seed rate and $\mathrm{V}=$ Variety.

Percentage of seedlings emerged from the seeds sown in the tray varied with the seed rate. Seedling emergence decreased with the increase in seed rate (Fig. 7).

In BR3, 77 percent seeds emerged and raised effective seedling for $100 \mathrm{~g}$ seed rate and gradually reduced to $56 \%$ seedling with the increase of seed rate up to $160 \mathrm{~g}$ tray $^{-1}$, whereas percentage of seedling emerged varied from 74 to $57 \%$ for BRRI dhan 28 and 71 to $54 \%$ for BRRI dhan50. Percentages of the seedlings emerged from the sown seeds decreased from 77 to $54 \%$ with increasing seed rate irrespective of the variety.

\section{Seedling quality}

Quality of the seedlings was measured in terms of seedling height, number of leaf, stem thickness, shoot dry weight, root-shoot ratio and seedling strength.

Seedling height. Significantly the highest seedling height was observed for extra-long and slender grain (Table 6). Averaged across the four varieties, plant height increased from 94 to $123 \mathrm{~mm}$ for $100 \mathrm{~g}, 107 \mathrm{~mm}$ to $119 \mathrm{~mm}$ for $130 \mathrm{~g}, 106$ to $118 \mathrm{~mm}$ for $140 \mathrm{~g}, 105$ to $115 \mathrm{~mm}$ for $150 \mathrm{~g}$ and 104 to $115 \mathrm{~mm}$ for $160 \mathrm{~g}$ seed rate. On average, $130 \mathrm{~g}$ seed rate gave the highest seedling height $(111.48 \mathrm{~mm})$.

Number of leaf. Variety and seed rate showed insignificant effect on leaf number of the raised seedling as were the single effect of variety. It was observed that leaf number decreased significantly with the increase of seed rate (Table 7 ).
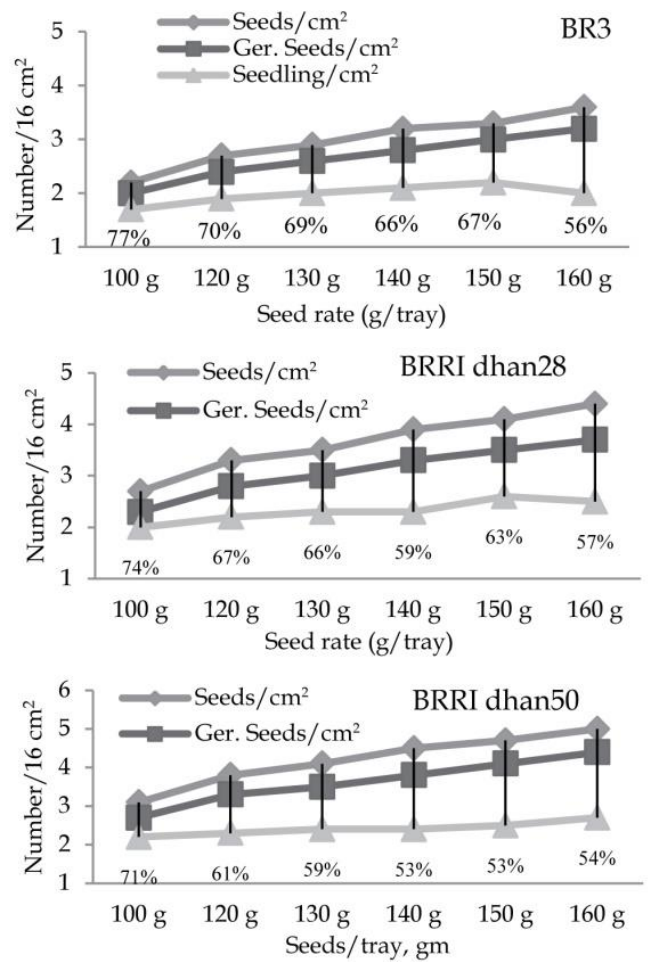

Fig. 7. Percentage of seedling emerged from the sown seeds under different seed rates and variety.

Stem thickness. Variety and seed rate demonstrated insignificant effect on stem thickness of the raised seedling (Table 8). BRRI dhan 28 under $100 \mathrm{~g}$ and $120 \mathrm{~g}_{\text {tray }}{ }^{-1}$ seed rate gave significantly higher stem thickness over other variety and seed rates. Stem thickness demonstrated reducing tendency with the increase of seed rate.

Shoot-dry weight. Variety and seed rate demonstrated insignificant effect whereas shoot dry weight varied significantly with variety and seed rate individually (Table 9). Shoot dry weight decreased with the increase in seed rate. Significantly the highest shoot dry weight was observed in BR3 followed by BRRI dhan50.

Root-shoot ratio. Root-shoot ratio of the seedling varied insignificantly with the twoway interaction of variety and seed rate (Table 10). However, it showed increasing tendency with the increase of seed rate. 
Seedling strength. Seedling strength was measured in terms of $\mathrm{mg} \mathrm{cm}^{-1}$ of shoot dry weight. Individually, variety and seed rate showed significant effect on seedling strength whereas two-way interaction demonstrated insignificant effect. Indeed, seedling strength decreased with the increase of seed rate (Table 11). The highest seedling strength $\left(0.043 \mathrm{mg} \mathrm{cm}^{-1}\right)$ was observed for the seed rate of $100 \mathrm{~g}$ of $\mathrm{BR} 3$ and the lowest $\left(0.020 \mathrm{mg} \mathrm{cm}^{-1}\right)$ for the seed rate of $160 \mathrm{~g}$ of BRRI dhan28.

Table 6. Seedling height $(\mathrm{mm})$ as affected by varietyand seed rate.

\begin{tabular}{lcccc}
\hline $\begin{array}{l}\text { Seed rate } \\
\left(\mathrm{g} \mathrm{tray}^{-1}\right)\end{array}$ & BR3 & $\begin{array}{c}\text { BRRI } \\
\text { dhan28 }\end{array}$ & $\begin{array}{c}\text { BRRI } \\
\text { dhan50 }\end{array}$ & Mean \\
\hline 100 & 104.7 & 94.4 & 123.2 & 107.4 \\
120 & 109.2 & 107.8 & 119.2 & 112.1 \\
130 & 106.4 & 111.4 & 118.5 & 112.1 \\
140 & 108.1 & 109.5 & 118.1 & 111.9 \\
150 & 107.1 & 106.1 & 115.0 & 109.4 \\
160 & 107.8 & 109.6 & 115.2 & 110.9 \\
Mean & 107.19 & 106.47 & 118.18 & \\
LSD 0.05 & $\mathrm{~V}=3.54$ & & & \\
CV, \% & 4.82 & & & \\
\hline
\end{tabular}

Note: $\mathrm{SR}=$ Seed rate and $\mathrm{V}=$ Variety.

Table 7. Number of leafs as affected by varietyand seed rate.

\begin{tabular}{lcccl}
\hline $\begin{array}{l}\text { Seed rate } \\
\left(\mathrm{g} \mathrm{tray}^{-1}\right)\end{array}$ & BR3 & $\begin{array}{c}\text { BRRI } \\
\text { dhan28 }\end{array}$ & $\begin{array}{c}\text { BRRI } \\
\text { dhan50 }\end{array}$ & Mean \\
\hline 100 & 2.4 & 1.9 & 1.8 & 2.0 \\
120 & 2.3 & 1.9 & 1.9 & 2.0 \\
130 & 1.8 & 1.9 & 1.7 & 1.8 \\
140 & 1.8 & 1.6 & 1.8 & 1.7 \\
150 & 1.9 & 1.5 & 1.5 & 1.6 \\
160 & 1.7 & 1.8 & 1.5 & 1.7 \\
Mean & 1.97 & 1.76 & 1.70 & - \\
LSD $_{0.05}$ & SR=NS & & & \\
CV, \% & 17.24 & & & \\
\hline
\end{tabular}

Note: $S R=$ Seed rate and $V=$ Variety.

Table 8. Stem thickness $(\mathrm{mm})$ of the raised seedling by variety and seed rate.

\begin{tabular}{lcccr}
\hline $\begin{array}{l}\text { Seed rate } \\
\left(\mathrm{g} \mathrm{tray}^{-1}\right)\end{array}$ & BR3 & $\begin{array}{c}\text { BRRI } \\
\text { dhan28 }\end{array}$ & $\begin{array}{c}\text { BRRI } \\
\text { dhan50 }\end{array}$ & Mean \\
\hline 100 & 1.2 & 1.2 & 1.2 & 1.2 \\
120 & 1.2 & 1.2 & 1.1 & 1.2 \\
130 & 1.2 & 1.1 & 1.2 & 1.2 \\
140 & 1.1 & 1.1 & 1.1 & 1.1 \\
150 & 1.1 & 1.1 & 1.0 & 1.1 \\
\hline
\end{tabular}

Table 8. Continued.

\begin{tabular}{lcccr}
\hline $\begin{array}{l}\text { Seed rate } \\
\left(\mathrm{g} \mathrm{tray}^{-1}\right)\end{array}$ & BR3 & $\begin{array}{c}\text { BRRI } \\
\text { dhan28 }\end{array}$ & $\begin{array}{c}\text { BRRI } \\
\text { dhan50 }\end{array}$ & Mean \\
\hline 160 & 1.0 & 1.0 & 1.1 & 1.0 \\
Mean & $\mathbf{1 . 1}$ & $\mathbf{1 . 1}$ & $\mathbf{1 . 1}$ & - \\
$\mathrm{LSD}_{0.05}$ & $\mathrm{~V}=0.06$ and $\mathrm{SR}=0.08$ & & \\
$\mathrm{CV}, \%$ & 8.21 & & & \\
\hline
\end{tabular}

Note: $\mathrm{SR}=$ Seed rate and $\mathrm{V}=$ Variety.

Table 9. Shoot dry weight (g) of the raised seedling as affected by variety and seed rate.

\begin{tabular}{lcccc}
\hline $\begin{array}{l}\text { Seed rate } \\
\left(\mathrm{g} \mathrm{tray}^{-1}\right)\end{array}$ & BR3 & $\begin{array}{c}\text { BRRI } \\
\text { dhan28 }\end{array}$ & $\begin{array}{c}\text { BRRI } \\
\text { dhan50 }\end{array}$ & Mean \\
\hline 100 & 0.45 & 0.24 & 0.39 & 0.36 \\
120 & 0.44 & 0.25 & 0.37 & 0.35 \\
130 & 0.41 & 0.23 & 0.37 & 0.34 \\
140 & 0.36 & 0.23 & 0.35 & 0.31 \\
150 & 0.37 & 0.22 & 0.34 & 0.31 \\
160 & 0.36 & 0.22 & 0.34 & 0.31 \\
Mean & 0.40 & 0.23 & 0.34 & \\
$\mathrm{LSD}_{0.05}$ & $\mathrm{~V}=0.06$ and SR=0.08 & & \\
$\mathrm{CV}_{,} \%$ & 8.67 & & & \\
\hline
\end{tabular}

Table 10. Root-shoot ratio of the raised seedling as affected by variety and seed rate.

\begin{tabular}{lcccc}
\hline $\begin{array}{l}\text { Seed rate } \\
\left(\mathrm{g} \mathrm{tray}^{-1}\right)\end{array}$ & BR3 & $\begin{array}{c}\text { BRRI } \\
\text { dhan28 }\end{array}$ & $\begin{array}{c}\text { BRRI } \\
\text { dhan50 }\end{array}$ & Mean \\
\hline 100 & 1.48 & 1.13 & 1.21 & 1.27 \\
120 & 1.45 & 1.21 & 1.18 & 1.28 \\
130 & 1.38 & 1.15 & 1.11 & 1.21 \\
140 & 1.19 & 1.22 & 1.09 & 1.17 \\
150 & 1.35 & 1.14 & 1.08 & 1.19 \\
160 & 1.25 & 1.09 & 1.07 & 1.14 \\
Mean & 1.35 & 1.16 & 1.12 & \\
LSD 0.05 & $\mathrm{~V}=0.11$ & & & \\
CV $\%$ & 13.85 & & & \\
\hline
\end{tabular}

Table 11. Seedling strength $\left(\mathrm{mg} \mathrm{cm}^{-1}\right)$ as affected by variety and seed rate.

\begin{tabular}{lcccc}
\hline $\begin{array}{l}\text { Seed rate } \\
\left(\mathrm{g} \mathrm{tray}^{-1}\right)\end{array}$ & BR3 & $\begin{array}{c}\text { BRRI } \\
\text { dhan28 }\end{array}$ & $\begin{array}{c}\text { BRRI } \\
\text { dhan50 }\end{array}$ & Mean \\
\hline 100 & 0.043 & 0.026 & 0.030 & 0.033 \\
120 & 0.041 & 0.023 & 0.030 & 0.031 \\
130 & 0.039 & 0.021 & 0.029 & 0.030 \\
140 & 0.033 & 0.021 & 0.028 & 0.027 \\
150 & 0.034 & 0.021 & 0.029 & 0.028 \\
160 & 0.033 & 0.020 & 0.029 & 0.027 \\
Mean & 0.037 & 0.022 & 0.029 & \\
LSD 0.05 & V=0.002 and SR=0.002 & & \\
CV, \% & 8.68 & & & \\
\hline Note: SR=Seed rate and V=Variety. & & \\
\end{tabular}


TRANS PLANTER PERFORMANCE

\section{Short and bold grain (cv. BR3)}

Seedling hill ${ }^{-1}$. Seed rates and seedling adjustment options showed significant effect on seedlings hill-1. Seedlings hill- ${ }^{-1}$ increased with the increase of seed rate and seedling adjustment options (Table 12). Seedlings hill-1 was found maximum for the seed rates of 140 to $160 \mathrm{~g}$ tray $^{-1}$ and seedling adjustment options 8 to 9 . Desired number of seedlings per hill was obtained for the seed rate of 140 to $150 \mathrm{~g}$ and seedling adjustment options 4 to 7 .

Damage seedling stroke-1. Damaged seedlings per stroke were directly related with the density of seedling and seedlings per hill. Interaction of seed rates and seedling adjustment options showed significant effect on damage seedlings per strokes as were single effect of seed rate and seedling adjustment options (Table 12). Damaged seedlings stroke${ }^{1}$ increased with the increase of both the seed rates and seedling adjustment options. Maximum number of seedling damage was observed for the seed rates of 140 to $160 \mathrm{~g}$ and seedling adjustment options 8 to 9 . It was found moderate for the seed rate of 130 to 150 $\mathrm{g}$ and seedling adjustment options 4 to 6 .

Percentage of missing hills. The twoway interaction effect of seed rates and seedling adjustment options of the rice transplanter showed significant effect on percentage of missing hills as were single effect of seed rates and seedling adjustment options (Table 12). Percentage of missing hills decreased with the increase of seed rate and seedling adjustment options. Percentage of missing hills was observed maximum for 100 to $130 \mathrm{~g}$ seed rate and 1 to 3 seedling adjustment options. It was found moderate for the seed rate of 140 to $160 \mathrm{~g}$ and 4 to 7 seedling adjustment options.

Medium and slender grain (cv. BRRI dhan28) Seedlings hill-1. Seed rates and seedling adjustment options of the rice transplanter showed insignificant effect on seedlings dispensed per hill whereas single effect of seed rates and seedling adjustment options showed significant effect. Seedlings per hill increased with the increase of seed rates and seedling adjustment options (Table 13). Seedlings per hill were found maximum for the seed rates of 150 to $160 \mathrm{~g}$ and 130 to $160 \mathrm{~g}$ under seedling adjustment options 7 to 8 and 9, respectively. Desired number of seedlings per hill was found for the seed rate of 130 to $160 \mathrm{~g}$ and seedling adjustment options 4 to 6 .

Damaged seedlings stroke ${ }^{-1}$. Damaged seedlings per stroke are directly related to the density of seedling and seedling per hill. Seed rate and seedling adjustment options showed significant effect on damaged seedling per stroke along with the single effect of seed rate and seedling adjustment options (Table 13). Damage of seedlings per stroke increased with the increase of both seed rates and seedling adjustment options. Maximum number of seedling damage was observed for the seed rates of 140 to $160 \mathrm{~g}$ and nine seedling adjustment options. It was found moderate for the seed rate of 130 to $150 \mathrm{~g}$ and seedling adjustment options 3 to 6 .

Percentage of missing hills. Seed rates and seedling adjustment options of the rice transplanter showed significant effect on percentage of missing hills along with the single effect of seed rates and seedling adjustment options (Table 13). Percentage of missing hills decreased with the increase of seed rates and seedling adjustment options. Percentage of missing hills was observed maximum for 100 to $120 \mathrm{~g}$ seed rates and 1 to 3 seedling adjustment options. It was acceptable for the seed rate of 130 to $160 \mathrm{~g}$ and seedling adjustment options 5 to 7 .

\section{Extra-long and slender grain (cv. BRRI dhan50)}

Seedling hill-1. Effect of seed rates and seedling adjustment options showed significant effect on seedlings per hill. 
Seedlings per hill increased with the increase of seed rates and seedling adjustment options (Table 14). Seedlings per hill found maximum for the seed rate of 130 to $160 \mathrm{~g}$ and seedling adjustment options 8 to 9 . It was found optimum for the seed rates of 120 to $140 \mathrm{~g}$ and seedling adjustment options 4 to 7 .

Damage seedling stroke-1. Damage seedlings per stroke are directly related with the density of seedling and seedling per hill. Interaction of seed rates and seedling adjustment options showed significant effect on damaged seedlings per stroke along with the single effect of seed rates and seedling adjustment options (Table 14). Damaged seedlings per stroke increased with the increase of both seed rate and seedling adjustment options. Maximum number of seedling damage was observed for the seed rates of 140 to $160 \mathrm{~g}$ and seedling adjustment options 8 to 9 . It was found moderate for the seed rates of 120 to $140 \mathrm{~g}$ and seedling adjustment options 4 to 7 .

Percentage of missing hills. Seed rates and seedling adjustment options of the rice transplanter showed significant effect on percentage of missing hills along with the single effect of seed rates and seedling adjustment options (Table 14).

Table 12. Transplanter performance as affected by seed rates of BR3 and seedling adjustment options of the rice transplanter.

\begin{tabular}{|c|c|c|c|c|c|c|c|c|c|c|}
\hline \multirow{2}{*}{$\begin{array}{l}\text { Seed rate } \\
\left(\mathrm{g} \mathrm{tray}^{-1}\right)\end{array}$} & \multicolumn{9}{|c|}{ Seedling adjustment option } & \multirow[t]{2}{*}{ Mean } \\
\hline & 1 & 2 & 3 & 4 & 5 & 6 & 7 & 8 & 9 & \\
\hline \multicolumn{11}{|c|}{ Seedling hill-1 } \\
\hline 100 & 2.3 & 2.5 & 2.7 & 2.9 & 3.1 & 3.4 & 3.7 & 4.1 & 4.5 & 3.2 \\
\hline 130 & 3.0 & 3.3 & 3.5 & 3.8 & 4.2 & 4.5 & 4.9 & 5.2 & 5.8 & 4.3 \\
\hline 140 & 3.2 & 3.5 & 4.0 & 4.2 & 4.5 & 4.8 & 5.2 & 5.6 & 6.2 & 4.6 \\
\hline Mean & 2.9 & 3.2 & 3.5 & 3.8 & 4.1 & 4.6 & 4.8 & 5.2 & 5.7 & - \\
\hline $\mathrm{LSD}_{0.05}$ & \multicolumn{10}{|c|}{$\mathrm{SR}=0.29$ and $\mathrm{SAP}=0.35$} \\
\hline $\mathrm{CV}, \%$ & 6.22 & & & & & & & & & \\
\hline \multicolumn{11}{|c|}{ Damage seedling stroke-1 } \\
\hline 100 & 0.2 & 0.2 & 0.2 & 0.7 & 0.7 & 0.9 & 1.6 & 2.0 & 2.5 & 1.0 \\
\hline 160 & 0.8 & 0.8 & 1.1 & 1.5 & 1.7 & 2.0 & 2.1 & 2.8 & 4.0 & 1.9 \\
\hline Mean & 0.7 & 0.7 & 0.8 & 1.8 & 2.0 & 2.3 & 2.8 & 3.2 & 3.9 & - \\
\hline $\mathrm{LSD}_{0.05}$ & \multicolumn{10}{|c|}{$\mathrm{SR}=0.08$ and $\mathrm{SAP}=0.10$ and $\mathrm{SR} \times \mathrm{SAP}=0.25$} \\
\hline $\mathrm{CV}, \%$ & 7.77 & & & & & & & & & \\
\hline \multicolumn{11}{|c|}{ Percentage of missing hill } \\
\hline 100 & 26.4 & 24.5 & 22.5 & 18.6 & 18.6 & 16.6 & 18.6 & 15.7 & 13.7 & 19.5 \\
\hline 120 & 22.4 & 20.4 & 19.5 & 18.5 & 15.6 & 14.6 & 13.6 & 10.7 & 9.7 & 16.1 \\
\hline 130 & 15.6 & 14.6 & 13.6 & 11.7 & 7.8 & 7.3 & 7.0 & 6.6 & 6.8 & 10.1 \\
\hline 140 & 12.7 & 11.7 & 10.7 & 9.8 & 7.6 & 6.8 & 6.4 & 5.3 & 4.9 & 8.4 \\
\hline 150 & 12.7 & 12.7 & 9.7 & 9.7 & 7.4 & 6.8 & 6.0 & 4.9 & 2.9 & 8.1 \\
\hline
\end{tabular}


Table 13. Transplanter performance as affected by seed rates of BRRI dhan 28 and seedling adjustment options of the rice transplanter.

\begin{tabular}{|c|c|c|c|c|c|c|c|c|c|c|}
\hline \multirow{2}{*}{$\begin{array}{l}\text { Seed rate } \\
\left(\mathrm{g} \mathrm{tray}^{-1}\right)\end{array}$} & \multicolumn{9}{|c|}{ Seedling adjustment option } & \multirow[t]{2}{*}{ Mean } \\
\hline & 1 & 2 & 3 & 4 & 5 & 6 & 7 & 8 & 9 & \\
\hline \multicolumn{11}{|c|}{ Seedling hill-1 } \\
\hline 100 & 2.7 & 2.9 & 3.2 & 3.3 & 3.7 & 3.9 & 4.0 & 4.7 & 5.2 & 3.7 \\
\hline 120 & 3.2 & 3.5 & 3.8 & 4.0 & 4.5 & 4.8 & 5.2 & 5.7 & 5.6 & 4.5 \\
\hline 130 & 3.3 & 3.7 & 4.0 & 4.2 & 4.6 & 5.0 & 5.4 & 5.9 & 6.5 & 4.7 \\
\hline 140 & 3.3 & 3.6 & 3.8 & 4.2 & 4.4 & 4.9 & 5.3 & 5.9 & 6.4 & 4.7 \\
\hline 150 & 3.9 & 4.3 & 4.6 & 5.0 & 5.4 & 5.7 & 6.3 & 6.7 & 7.5 & 5.5 \\
\hline 160 & 3.8 & 4.2 & 4.3 & 4.9 & 5.3 & 5.4 & 6.2 & 6.5 & 7.3 & 5.3 \\
\hline Mean & 3.4 & 3.7 & 4.0 & 4.3 & 4.7 & 5.0 & 5.4 & 5.9 & 6.4 & - \\
\hline LSD $_{0.05}$ & \multicolumn{10}{|c|}{$\mathrm{SR}=0.28$ and $\mathrm{SAP}=0.34$} \\
\hline CV,$\%$ & 5.39 & & & & & & & & & \\
\hline \multicolumn{11}{|c|}{ Damage seedling stroke ${ }^{-1}$} \\
\hline 100 & 0.2 & 0.5 & 0.5 & 0.5 & 0.7 & 0.9 & 0.9 & 1.4 & 1.9 & 0.9 \\
\hline 120 & 0.5 & 0.9 & 1.2 & 0.7 & 1.2 & 1.6 & 1.9 & 2.1 & 2.8 & 1.4 \\
\hline 130 & 0.7 & 0.9 & 1.4 & 1.6 & 1.4 & 2.1 & 2.1 & 2.6 & 3.0 & 1.8 \\
\hline 140 & 0.9 & 1.2 & 1.6 & 1.6 & 1.4 & 2.3 & 2.6 & 1.6 & 4.0 & 1.9 \\
\hline 150 & 0.9 & 1.2 & 1.6 & 1.8 & 1.8 & 2.3 & 2.6 & 3.0 & 4.0 & 2.2 \\
\hline 160 & 0.7 & 1.0 & 1.4 & 1.7 & 1.4 & 3.1 & 2.4 & 3.1 & 4.6 & 2.2 \\
\hline Mean & 0.7 & 1.0 & 1.3 & 1.3 & 1.3 & 2.1 & 2.1 & 2.3 & 3.4 & - \\
\hline $\mathrm{LSD}_{0.05}$ & \multicolumn{10}{|c|}{$\mathrm{SR}=0.044$ and $\mathrm{SAP}=0.054$ and $\mathrm{SR} \times \mathrm{SAP}=0.131$} \\
\hline $\mathrm{CV}, \%$ & 4.73 & & & & & & & & & \\
\hline \multicolumn{11}{|c|}{ Percentage of missing hill } \\
\hline 100 & 24.3 & 21.4 & 20.4 & 17.5 & 17.5 & 14.6 & 14.6 & 13.6 & 11.7 & 17.3 \\
\hline 120 & 20.4 & 19.4 & 20.4 & 17.5 & 14.6 & 12.6 & 11.7 & 10.7 & 8.8 & 15.1 \\
\hline 130 & 15.6 & 14.6 & 12.7 & 11.7 & 7.8 & 7.8 & 6.8 & 6.8 & 5.8 & 10.0 \\
\hline 140 & 11.7 & 10.7 & 10.7 & 9.7 & 7.0 & 6.6 & 5.8 & 4.9 & 3.9 & 7.9 \\
\hline 150 & 12.7 & 9.8 & 9.8 & 8.8 & 6.8 & 6.8 & 5.7 & 3.9 & 2.0 & 7.4 \\
\hline 160 & 11.7 & 12.7 & 8.8 & 8.8 & 6.6 & 6.9 & 6.0 & 4.9 & 3.9 & 7.8 \\
\hline Mean & 16.1 & 14.8 & 13.8 & 12.3 & 10.1 & $9.2 \mathrm{f}$ & $8.4 \mathrm{~g}$ & 7.5 & 6.0 & - \\
\hline LSD $_{0.05}$ & \multirow{2}{*}{\multicolumn{10}{|c|}{$\begin{array}{l}\mathrm{SR}=0.095 \text { and } \mathrm{SAP}=0.12 \text { and } \mathrm{SR} \times \mathrm{SAP}=0.285 \\
1.62\end{array}$}} \\
\hline$C V, \%$ & & & & & & & & & & \\
\hline
\end{tabular}

Note: $\mathrm{SR}=$ Seed rate and $\mathrm{SAP}=$ Seedling adjustment options.

Table 14. Transplanter performance as affected by seed rates of BRRI dhan50 and seedling adjustment options of the transplanter.

\begin{tabular}{|c|c|c|c|c|c|c|c|c|c|c|}
\hline \multirow{2}{*}{$\begin{array}{l}\text { Seed rate } \\
\left(\mathrm{g} \text { tray }^{-1}\right)\end{array}$} & \multicolumn{9}{|c|}{ Seedling adjustment option } & \multirow[t]{2}{*}{ Mean } \\
\hline & 1 & 2 & 3 & 4 & 5 & 6 & 7 & 8 & 9 & \\
\hline \multicolumn{11}{|c|}{ Seedling hill-1 } \\
\hline 100 & 3.0 & 3.3 & 3.6 & 3.9 & 4.1 & 4.4 & 4.8 & 5.3 & 5.8 & 4.2 \\
\hline 120 & 3.2 & 3.6 & 3.8 & 4.0 & 4.4 & 5.2 & 5.2 & 5.7 & 6.3 & 4.6 \\
\hline 130 & 3.5 & 3.8 & 4.2 & 4.5 & 4.9 & 5.2 & 5.6 & 6.1 & 6.7 & 5.0 \\
\hline 140 & 3.5 & 3.8 & 4.1 & 4.4 & 4.8 & 5.1 & 5.5 & 6.2 & 6.7 & 4.9 \\
\hline 150 & 3.7 & 4.1 & 4.5 & 4.8 & 5.1 & 5.6 & 6.0 & 6.5 & 7.2 & 5.3 \\
\hline 160 & 4.1 & 4.5 & 4.9 & 5.2 & 5.6 & 6.1 & 6.6 & 7.2 & 7.9 & 5.8 \\
\hline Mean & 3.5 & 3.9 & 4.2 & 4.5 & 4.8 & 5.3 & 5.6 & 6.2 & 6.8 & - \\
\hline $\mathrm{LSD}_{0.05}$ & \multicolumn{10}{|c|}{$\mathrm{SR}=0.313, \mathrm{SAP}=0.384, \mathrm{SR} \times \mathrm{SAP}=\mathrm{NS}$} \\
\hline $\mathrm{CV}, \%$ & & & & & & & & & & \\
\hline \multicolumn{11}{|c|}{ Damage seedling stroke-1 } \\
\hline 100 & 0.5 & 1.0 & 1.0 & 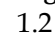 & 1.4 & 1.4 & 1.9 & 2.4 & 2.8 & 1.5 \\
\hline 120 & 1.0 & 1.0 & 1.0 & 1.2 & 1.4 & 1.9 & 1.9 & 2.4 & 2.8 & 1.6 \\
\hline 130 & 1.0 & 1.0 & 1.4 & 1.3 & 1.4 & 2.4 & 2.4 & 2.4 & 2.8 & 1.8 \\
\hline 140 & 1.0 & 1.4 & 1.4 & 1.4 & 1.9 & 2.4 & 2.4 & 2.8 & 3.3 & 2.0 \\
\hline 150 & 1.0 & 1.4 & 1.4 & 1.8 & 1.9 & 2.4 & 2.4 & 2.8 & 3.3 & 2.0 \\
\hline
\end{tabular}


Table 14. Continued.

\begin{tabular}{|c|c|c|c|c|c|c|c|c|c|c|}
\hline \multirow{2}{*}{$\begin{array}{l}\text { Seed rate } \\
\left(\mathrm{g} \mathrm{tray}^{-1}\right)\end{array}$} & \multicolumn{9}{|c|}{ Seedling adjustment option } & \multirow[t]{2}{*}{ Mean } \\
\hline & 1 & 2 & 3 & 4 & 5 & 6 & 7 & 8 & 9 & \\
\hline 160 & 1.0 & 1.4 & 1.0 & 1.9 & 2.4 & 2.8 & 3.1 & 3.3 & 3.3 & 2.2 \\
\hline Mean & 0.9 & 1.2 & 1.2 & 1.5 & 1.7 & 2.2 & 2.3 & 2.7 & 3.1 & - \\
\hline $\mathrm{LSD}_{0.05}$ & \multicolumn{10}{|c|}{$\mathrm{SR}=0.0527$ and $\mathrm{SAP}=0.0645$ and $\mathrm{SR} \times \mathrm{SAP}=0.158$} \\
\hline $\mathrm{CV}, \%$ & \multicolumn{10}{|c|}{5.25} \\
\hline \multicolumn{11}{|c|}{ Percentage of missing hills } \\
\hline 100 & 17.6 & 14.7 & 13.7 & 11.7 & 11.7 & 12.7 & 8.8 & 8.8 & 7.8 & 11.9 \\
\hline 120 & 14.7 & 10.8 & 10.4 & 7.7 & 7.5 & 5.9 & 4.0 & 5.9 & 2.9 & 7.7 \\
\hline 130 & 12.7 & 9.8 & 10.4 & 7.8 & 6.9 & 5.9 & 4.4 & 4.9 & 2.9 & 7.3 \\
\hline 140 & 10.7 & 9.8 & 9.8 & 7.8 & 6.8 & 5.9 & 3.9 & 2.0 & 1.0 & 6.4 \\
\hline 150 & 10.8 & 8.8 & 6.9 & 6.9 & 5.9 & 5.9 & 4.9 & 2.9 & 2.9 & 6.2 \\
\hline 160 & 10.8 & 8.8 & 8.8 & 4.9 & 3.9 & 2.9 & 2.0 & 1.0 & 1.0 & 4.9 \\
\hline Mean & 12.9 & 10.4 & 10.0 & 7.8 & 7.1 & 6.5 & 4.7 & 4.2 & 3.1 & - \\
\hline $\mathrm{LSD}_{0.05}$ & \multirow{2}{*}{\multicolumn{10}{|c|}{$\begin{array}{c}\mathrm{SR}=0.0758 \text { and } \mathrm{SAP}=0.0929 \text { and } \mathrm{SR} \times \mathrm{SAP}=0.227 \\
1.9\end{array}$}} \\
\hline $\mathrm{CV}, \%$ & & & & & & & & & & \\
\hline
\end{tabular}

Note: $\mathrm{SR}=$ Seed rate and $\mathrm{SAP}=$ Seedling adjustment option

Percentage of missing hills decreased with the increase of seed rates and seedling adjustment options. Percentage of missing hills was maximum for the seed rates of 100 to $130 \mathrm{~g}$ and 1 to 3 seedling adjustment options. It was found optimum for the seed rates of 120 to $150 \mathrm{~g}$ and 4 to 7 seedling adjustment options.

\section{DISCUSSION}

Transplanting is the most widespread planting technique for rice production in Asia (IRRI, 2002). Mechanical transplanting becomes more and more popular recently because of labour crisis during transplanting period. To obtain high yield by the transplanting method, nursery culture is of prime importance to provide healthy and vigorous seeding. Optimization of seedling density was measured with the many parameters described as follows.

Number of seeds per unit area influenced directly with the seed rate in the tray. Thousand grain weight (TGW) and grain type also affected the number of seeds per unit area. For the same seed rate, number of seeds per unit area was observed more for BRRI dhan50 and less for BR3 because of more TGW of BR3 (27.75 g) and less of BRRI dhan50 $(19.64 \mathrm{~g})$. Seed density varied significantly with the same seed rate for different types of varieties. Agri-Facts (2007) noticed that seed size and the TGW vary from one crop to another, between varieties of the same crop and even from year to year or from field to field of the same variety.

Seedlings per unit area depend on seed rate, germination percentage and survival rate of seedling. For indica rice, densities of 1.5 to 3 seedlings per $100 \mathrm{~mm}^{2}$ is required for minimizing the missing hills and maintain optimal number of seedlings hill-1 (CAME $^{\mathrm{b}}$, 2007). Seedling per unit area was observed statistically similar for the seed rate of 130 , 140,150 and $160 \mathrm{~g}^{\text {tray }}{ }^{-1}$ of BR3 grain (2.0 to 2.2 number $\mathrm{cm}^{-2}$ ) and BRRI dhan28 (2.3 to 2.6 number $\mathrm{cm}^{-2}$ ) because higher seed rate might be increased the mortality percentage of seedling whereas the lowest seedling per unit area was observed for $100 \mathrm{~g}$ (1.7 to 2.2 number $\mathrm{cm}^{-2}$ ) followed by $120 \mathrm{~g}$ (1.9 to 2.3 number $\mathrm{cm}^{-}$ 2) seed rate for the same varieties. In case of BRRI dhan50, seedlings per unit area were not varied significantly with the seed rate of 100 to $160 \mathrm{~g}$ per tray (2.2 to 2.7 number $\mathrm{cm}^{-2}$ ). The six different seed rate produced recommended seedling density of BRRI dhan50 because of less TGW. 
In BR3, percentage of effective seedling was reduced from 77 to $56 \%$ with the increase of seed rate from $100 \mathrm{~g}$ to $160 \mathrm{~g}$ tray $^{-1}$ which was reduced from 74 to $57 \%$ for BRRI dhan 28 and 71 to $54 \%$ for BRRI dhan50. Percentages of the seedlings emerged from the sown seeds decreased with the increase of seed rate irrespective of the variety for increasing the rate of mortality with the increasing of seed density. Considering the number of seedlings hill-1 and cost of saving, $140 \mathrm{~g}^{-1}$ tray $^{-1}$ of short and bold grain (cv. BR3), $130 \mathrm{~g}^{\mathrm{tray}^{-1}}$ for medium and slender grain (cv. BRRI dhan28) and $120 \mathrm{~g} \mathrm{tray}^{-1}$ for extra-long and slender grain (cv. BRRI dhan50)can be recommended for farmers.

Seedling characteristics were measured in terms of seedling length, number of leaf, stem thickness, shoot dry weight, root-shoot ratio and seedling strength. BRRI dhan 50 gave the highest seedling height due to genotypic cause. Seedling height also varied with the seed rate. BR3, BRRI dhan28 and BRRI dhan50 demonstrated higher seedling height for the seed rate of $120 \mathrm{~g}(109.2 \mathrm{~mm})$, $130 \mathrm{~g}(111.4 \mathrm{~mm})$ and $100 \mathrm{~g}(123.2 \mathrm{~mm})$, respectively. Based on appropriate seedling density, seed rate of $140 \mathrm{~g}$ for BR3, $130 \mathrm{~g}$ for BRRI dhan28 and $120 \mathrm{~g}$ for BRRI dhan50 gave seedling height of 180.1, 111.4and $119.2 \mathrm{~mm}$ respectively. Dhananchezhiyan et al. (2013) found maximum seedling height $170.6 \mathrm{~mm}$ under different organic soil media whereas optimum seedling height was $120 \mathrm{~mm}$ (CAMEa, 2007).

About three leaves stage and 120 to 150 $\mathrm{mm}$ height seedlings are required for machine transplanting (Kitagawa et al., 2004 and Manjunatha et al., 2009). Leaf number of the raised seedling decreased with the increase of seed irrespective of variety, which was 2.4 to $1.7,1.9$ to 1.5 and 1.9 to 1.5 for BR3, BRRI dhan 28 and BRRI dhan50 respectively. Stem thickness and shoot dry weight also decreased whereas root-shoot ratio and seedling strength increased with the increase of seed rate because of seedling density increased with the increase of seed rate that stunted the seedling resulting thin seedling. Shoot dry weight reduced with the thickness of the seedling, however seedling strength increased because of more dry matter per unit length.

Seedling per hill varied with seedling density on seedling mat and pre-setting of seedling adjustment options of the rice transplanter during mechanical transplanting. It also depends on the rice ecosystem, planting technique, seed quality and rice variety. Mechanical transplanter damaged some seedlings during transplanting and hence more seedlings hill- $^{-1}$ required than that of recommended seedling. Based on 4-6 seedlings hill-1 and 5 to 7 seedling adjustment options of the rice transplanter, optimum seed rate 140 to $160 \mathrm{~g}$ for short and bold grain (BR3), 130 to $150 \mathrm{~g}$ for medium and slender grain (BRRI dhan28) and 120 to $140 \mathrm{~g}$ for extra-long and slender grain (BRRI dhan50) were identified for mechanical transplanting of different types of grains. IRRI (2007) noticed that in most of the countries, farmers' plant 23 seedlings hill- $^{-1}$. For mechanical transplanting, seedlings hill-1 should be maintained 2-4 to obtain optimum plant population (Kumar et al., 2012 and Kamboj et al., 2013). Ramasamy et al. (1987) found that yield decreased with the increase of number of seedlings hill-1 more of 4 seedlings. Seed rate of mat type seedling in a tray should be 130$150 \mathrm{~g}$ resulting into seedling the planting density of 3-5 seedlings hill-1 (Hisashi et al., 2004). Behera et al. (2007) also stated that number of seedlings hill-1 should be more than 2.65 for better performance of the rice transplanter.

Damage of seedlings stroke- ${ }^{-1}$ varied with seedling density, seedlings hill-1 and presetting of seedling adjustment options of the rice transplanter because rotary picker damaged some seedling when passed through the seedling mat. It was also increased with 
transplanting speed and seedling age (Behera et al., 2007). Interaction of seed rate and preseedling adjustment options of the rice transplanter showed significant effect on seedling damage stroke- ${ }^{-1}$ of all types of varieties. Maximum seedling damage was observed for 140-160 g seed rate of all types of varities with the 8-9 seedling adjustment options of rice transplanter. For the recommended seed rate based on seedlings hill-1 $^{-1}$ pre-setting of seedling adjustment options of the rice transplanter obtained 5-7 for BR3 (140-160 g), 5-6 for BRRI dhan28 (130$150 \mathrm{~g}$ ) and 4-7 for BRRI dhan50 (120-140) for moderate rate of seedling damage per stroke. Damaged seedling increased with the increase of both seed rate and pre-setting adjustment options of the rice transplanter because of increasing seedling density and picker contract area during seedling collection from mat respectively.

Interaction effect of seed rate and presetting seedling adjustment options of the rice transplanter showed significant effect on percentage of missing hills. It was observed that percentage of missing hills decrease with the increase of seed rate and seedling adjustment options because of seedling density and more seedling released with the increase of seedling adjustment options. The missing hills decreased from 13.32 to $7.65 \%$ with the increasing of seeding rate from 60 to $100 \mathrm{~g}$ per tray (Alizadeh et al., 2011).

Maximum percentage of missing hills (12$26 \%$ ) was observed for 100-130 g seed rate and 1-3 pre-setting of seedling adjustment options of the rice transplanter because of less seedling density and less number of seedling realized by the rotary picker. Contrary to, 140$160 \mathrm{~g}$ seed rate with 5-7 seedling adjustment options for BR3, 130-150 g seed rate with 5-6 options also for BRRI dhan28 and 120-150 g seed rate with 4-7 optionsfor BRRI dhan50 gave $5-7 \%$ missing hills because of more seedling density and more seedlings realized by the picker. Behere et al. (2007) stated that the missing hill was not due to the transplanter but due to the non-uniformity of seedling in the mat.

\section{CONCLUSION}

Based on missing hills and number of seedlings hill-1, $140 \mathrm{~g}$ of seeds tray-1 for short and bold grain (cv. BR3) under the seedling adjustment option of 5 to $7,130 \mathrm{~g}$ of seeds tray $^{-1}$ for medium and slender grain (cv. BRRI dhan28) under the option of 5 to 7 also and $120 \mathrm{~g}$ of seeds tray ${ }^{-1}$ for extra-long and slender paddy (BRRI dhan50) under the option of 4 to 7 was found suitable to get optimum seedlings per hill and minimize missing hills.

\section{REFERENCES}

Adair, C R, C N Bollice, D H Bowman, N E Jodon, T H Jonhston, B D Webb and J GAtkins. 1973. Rice breeding and testing methods in the United States. Pages 22-75 In: Rice in the United States: varieties and production. US Dep. Agric. Handb. 289 (revised).

Agri-Facts. 2007. Practical information for Albert's Agricultural Industry. Using 1,000 K Weight for Calculating Seeding Rates and Harvest Losses. www1.agric.gov.ab.ca/\$department/deptdocs. nsf/all/agdex81/\$file/ 100_22-1.pdf?

Alizadeh, M R, A R Yadollahhinla and F R Ajdadi. 2011. Techno-economic performance of a selfpropelled rice transplanter and comparison with hand transplanting for hybrid rice variety. International Journal of Natural and Engineering Sciences, 5 (3): 27-30.

Anoop, D, R Khurana, S Jaskarn and S Gurusahib. 2007. Comparative performance of different paddy transplanters developed in India - A review, Agricultural Reviews, Dept. of Farm Power and Machinery, Punjab Agricultural University, Ludhiana, India, Year : 2007, Volume : 28, Issue : 4. Pp. 262-269.

Behera, B K, B P Varshney and S Swain. 2007. Influence of Seedling Mat Characteristics on Performance of Self-Propelled Rice Transplanter. Agricultural Engineering Today. Year: 2007, Volume: 31, Issue: 1: pp. 1-6. 
CAME $^{a}$ (Center of Agriculture Machinery Extension, Ministry of Agriculture, China). 2007. The training programme on rice field plowing and rice transplanting mechanization technology, organized by Ministry of Agriculture, PR China, 8-17 August 2007: 62-63.

CAMEb. 2007. Raising rice seedlings for mechanical transplanting. In: The training program on rice field plowing andrice transplanting mechanization technology textbook. pp-32.

Clayton, S. 2010. 50 years of rice science for a better world - and it's just the start! Rice. Today., IRRI.

Dhananchezhiyan, P, C D Durairaj and S P arveen. 2013. Development of nursery raising technique for "system of rice intensification" machine transplanting. African Journal of Agricultural Research. Vol. 8 (29), pp. 3873-3882, 1 August 2013.

FAO. 1972. Recommended Model Grading System for Rice in International Trade. Revised 1972. FAO Rome.

Gomez, K A and A A Gomez. 1984. Statistical Procedures in Agricultural Research, 2nd Edition, Wiley, New York. pp. 680.

Hisashi, K, H Shiratsuchi and A Ogura. 2004. Effect of seeding rate on the growth and quality of rice seedlings in the long-mat seedling culture system. In: Poster presentation in the $4^{\text {th }}$ international crop science congress, September 2004 Brisbane, Australia. www.cropscience.org.au/icsc 2004

IRRI. 2002. Rice almanac, 3rd end. LS Baños, Philippines: International Rice Research Institute.

IRRI. 2007. CropStat for Windows. Version 7.2.2007.3, IRRI, Metro Manila, Philippines.

Islam, A K M S, M A Rahman, A K M L Rahman, M T Islam and M I Rahman. 2016. Techno-economic performance of 4-row self-propelled mechanical rice transplanter at farmers' field in Bangladesh. Progressive Agriculture 27 (3): 369-382, 2016.

Kabir, W and S Ahmed. 2005. Status of research and development institutes on agricultural engineering in Bangladesh. Report presented during $4^{\text {th }}$ Sessions TC/GC meeting of Asia Pacific Center of Agricultural Engineering and Machinery (APCAEM) held during 21-24 Nov. 2005 in New Delhi, India.

Kamboj, B R, B Y Dharam, Y Ashok, K G Narender, G Gurjeet, K M Ram andS C Bhagirath. 2013. Mechanized transplanting of rice (Oryza sativa L.) in nonpuddled and no-till conditions in the rice-wheat cropping system in Haryana, India. American Journal of Plant Sciences. 4, 2409-2413 dx.doi.org/10.4236/ajps.2013.412298
Kitagawa, H, H Shiratsuchi and A Ogura. 2004. Effect of seeding rate on the growth and quality of rice seedlings in the long-mat seedling culture system. In: 4th International Crop Science Congress Brisbane, Australia, 26 Sep - 1 Oct.

Kumar, S, S S Singh, P K Sundaramand B P Bhatt. 2012. Agronomic Management and Production Technology of Unpuddled Mechanical Transplanted Rice. Published by the Director, ICAR. New Patel Nagar, New Delhi-110 008. Year 2012.

Manjunatha, M V and R B G Masthana, S D Shashidhar and V R Joshi. 2009. Studies on the performance of self-propelled rice transplanter and its effect on crop yield. Karnataka J. Agric. Sci. 22 (2): 385387.

Mann, R A and M Ashraf. 2001. Improvement of Basmati and its production practices in Pakistan. Specialty Rice of the World: Breeding, Production and Marketing. R. C. Chaudhary, D.V. Tran and R. Duffy (ed.) Food and Agricultural Organization of the United Nations, Rome. Pp: 129-148.

Munir, K S and J M K K Muaz. 2008. Forecasting demand for urea TSP and MP fertilizer for vegetable and rice production in Bangladesh. www.papers. ssrn.com/sol3/papers.cfm?abstract_id=1313585

Osunbitana, J A, D J Oyedele and K O Adekalu. 2005. Tillage effects on bulk density, hydraulic conductivity and strength of a loamy sand soil in southwestern Nigeria. Soil and Tillage Research. 82 (2005) 57-64.

Rahman, M R. 1997. Pesticide use and its impact on MV rice productivity and farmer's health. MS Thesis. Department of Agricultural Economics, BSMR Agricultural University, Salna, Gazipur.

Ramasamy, S, B Chandrasekuran and S Sunkaram. 1987. Effect of spacing and seedling per hill. International Rice Research News Letter. 12 (4): 9.

Runsick, S and C E Wilson. 2009. Agriculture and Natural Resources, University of Arkansas Division of Agriculture. FSA2157-PD-5-09Na.

Sattar, S A. 1999. A brief note on bridging the yield gap in Bangladesh. An unpublished report. Agronomy Division, BRRI, Gazipur.

Statistix 10 software. 2013. An analytical software of Statistix 10,Analytical Software Pub Date: 1/1/2013.

Ziauddin, A T M and S Ahmmed. 2010. Agricultural Research: Vision 2030 and Beyond. A final report on Research Priorities in Farm Machinery, Irrigation and Water Management and Postharvest Technology, Submitted to BARC, Dhaka, 2010. 
